\title{
Fabrication of Alternative Bolus for Cobalt-60 Teletherapy Using Two Locally Available Materials
}

\author{
Abayomi Moses Olaosun 1, *, Caleb Ayoade Aborisade ${ }^{1,2}$, Iyobosa Blessing Uwadiae ${ }^{3}$, \\ Denen Eric Shian ${ }^{1}$, Fatai Akintunde Balogun ${ }^{4}$ \\ ${ }^{1}$ Department of Physics and Engineering Physics, Obafemi Awolowo University, Ile-Ife, Nigeria \\ ${ }^{2}$ Department of Physical Sciences, First Technical University, Ibadan, Nigeria \\ ${ }^{3}$ Department of Radiation Oncology, University College Hospital, Ibadan, Nigeria \\ ${ }^{4}$ Center of Energy Research and Development, Obafemi Awolowo University, Ile-Ife, Nigeria
}

Email address:

olaosunabayomi@yahoo.com (A. M. Olaosun)

${ }^{*}$ Corresponding author

\section{To cite this article:}

Abayomi Moses Olaosun, Caleb Ayoade Aborisade, Iyobosa Blessing Uwadiae, Denen Eric Shian, Fatai Akintunde Balogun. Fabrication of Alternative Bolus for Cobalt-60 Teletherapy Using Two Locally Available Materials. Engineering Physics. Vol. 4, No. 1, 2020 , pp. 15-18. doi: $10.11648 /$ j.ep.20200401.13

Received: April 9, 2020; Accepted: June 8, 2020; Published: August 4, 2020

\begin{abstract}
Bolus is a tissue equivalent material which is use in radiation therapy in order to eliminate skin sparing effect of higher energy photon beams that always reduce the surface dose. There are several commercially bolus material such as Superflab, Aquaplast and gels for use but literature have shown that they are expensive and are not readily available in developing countries. This work presents the fabrication of an alternative bolus for Cobalt-60 Teletherapy using two locally available materials (Beeswax and Petroleum jelly). Beeswax was liquefied at a temperature of $60^{\circ} \mathrm{C}$ followed by the addition of Petroleum jelly at ratio 3:1 by weight for proper molding and flexibility. In order to determine the depth of maximum dose, Thermoluminescent Dosimeter (TLD) chips were inserted in between ten bolus materials of thickness $0.5 \mathrm{~cm}$ that were arranged in layers and placed on a solid water phantom. This was then irradiated with Cobalt-60 radiation source using field size ranging from $5 \mathrm{~cm} \times 5 \mathrm{~cm}$ to $10 \mathrm{~cm} \times 10 \mathrm{~cm}$ field size. For all the field size, maximum absorbed dose was found to be at $0.5 \mathrm{~cm}$ depth. This depth of maximum dose was compared to two tissue equivalent materials in use in radiation therapy: water and Superflab for Cobalt-60 Teletherapy and found to be in agreement. The percentage dose deviation when compared with water for $1 \mathrm{~cm}, 2 \mathrm{~cm}, 3 \mathrm{~cm}, 4 \mathrm{~cm}$ and $5 \mathrm{~cm}$ were less than $2 \%$. The flexibility of the bolus material and the analysis of the absorbed dose measured have shown that the fabricated bolus material of thickness $0.5 \mathrm{~cm}$ can be used as an alternative bolus material for Cobalt-60 Teletherapy.
\end{abstract}

Keywords: Bolus Materials, Absorbed Dose, Cobalt-60, Teletherapy, Field Size

\section{Introduction}

In radiation therapy, the use of megavoltage photon beams usually exhibit skin sparing effect. This skin sparing effect is advantageous in the treatment of tumours below the skin surface [1]. This is true for deep-seated tumours. Skin sparing effect is a major challenge for superficial tumours because it always causes the dose at the skin surface $\left(\mathrm{d}_{\text {surf }}\right)$ to be lower when compared to the maximum dose at a certain depth $\left(d_{\max }\right)$ below the skin surface during treatment [2]. The enhancement of the surface dose will eliminate the skin sparing effect and thus increasing the surface dose if bolus is placed on the skin surface [2]. According to Walker (2005), bolus is defined as a tissue equivalent materials which when it is positioned around the irradiated area it results in an additional build up causing the maximum dose to occur at the skin surface [3]. It is required that bolus material should be innocuous, flexible, easily produced, inexpensive [4] and interact with radiation, like the part of the body it mimic or mostly like water $[3,5]$. It is expected that the thickness of bolus material for Cobalt-60 energy beam source should be about $0.5 \mathrm{~cm}$ since maximum dose usually occurs at a depth 
of $0.5 \mathrm{~cm}$ for this source [6].

In dosimetric simulations of higher energy beams radiotherapy, water is used as the reference material [7] since the body is composed of about 65 percent of water. Therefore, it is recommended that bolus should not introduce an absorbed dose uncertainty that is more than 1 percent [5] and dose deviation should not be more than $2 \%$ except at some point [8].

Several commercially bolus material such as Superflab, Aquaplast and gels have been developed for use but literature have shown that they are expensive and they are not readily available in developing countries [6,9]. Thus, this work aims at fabricating an alternative low cost bolus using locally available materials.

Beeswax has been characterized and reported as a good base tissue substitute option in external higher energy photon beams. It has a higher concentration of hydrogen, oxygen, carbon and nitrogen, but it is not flexible [7]. Thus, it cannot be used alone as bolus since a good bolus must be flexible. Petroleum jelly which is a mixture of hydrocarbons has been used as a tissue equivalent material with a physical density similar to that of human tissue [10]. Beeswax becomes softer when petroleum jelly is added to it [11]. For this reason, beeswax and petroleum jelly were chosen in this work for the fabrication of alternative bolus material for Cobalt-60 Teletherapy.

\section{Method}

Beeswax was obtained from a local farmer at the Teaching and Research farm of the Obafemi Awolowo University, (OAU) Ile-Ife. It has an empirical formula of $\mathrm{C}_{15} \mathrm{H}_{31} \mathrm{COOC}_{30} \mathrm{H}_{61}$, a density of about 0.958 to $0.970 \mathrm{~g} / \mathrm{m}^{3}$ at $15^{\circ} \mathrm{C}$, a melting point of $64^{\circ} \mathrm{C}$ [12]. The Petroleum Jelly was purchased from a local store. Petroleum jelly is a mixture of hydrocarbons having a physical density of $0.83 \mathrm{~g} / \mathrm{cm}^{3}$ [10]. The Gammabeam X200 Cobalt-60 Teletherapy machine located at the National Institute of Radiation Protection and Research (NIRPR), University of Ibadan, Ibadan was used as the radiation source. The machine is a research irradiator which consists of a Cobalt-60 radiation source with collimators and laser light accessories. For the purpose of backscattering radiation, water phantom of dimensions $30 \mathrm{~cm}$ $\times 30 \mathrm{~cm} \times 15 \mathrm{~cm}$ was also supplied by the institute. Sixty six (66) well-labeled calibrated Thermoluminescent Dosimeter (TLD) chips obtained from the TLD Laboratory of the Department of Physics and Engineering Physics, OAU, IleIfe were used. The TLD chips are tissue equivalent and can be used to measures exposure to ionizing radiation. All exposures for calibration of reader and dosimeter chips were carried out in the secondary standards dosimetry laboratory at NIRPR where a national radiation dose standard was maintained. The NIRPR serves as the custodian of the national secondary standards traceable with traceability to the IAEA standard laboratory in Vienna.

The beeswax was first placed inside a container and liquefied by heating it to a temperature of $64^{\circ} \mathrm{C}$ followed by addition of petroleum jelly at a ratio of about 3:1 by weight for proper molding and flexibility. Thereafter, about 30 minutes was given for the resulting mixture to cool, after which it was stirred thoroughly and molded on polythene. Necessary corrections were done on the material by adjusting its thickness to $0.5 \mathrm{~cm}$ using micrometer screw gauge for proper measurement, while the length and the breadth of the material were also adjusted to $10 \mathrm{~cm}$ each using a metre rule. In the order described above, ten bolus materials were fabricated in this way.

Ten bolus materials each of dimensions $10 \mathrm{~cm} \times 10 \mathrm{~cm} \times$ $0.5 \mathrm{~cm}$ were arranged in layers making a sum thickness of 5 $\mathrm{cm}$. This arrangement allowed the TLDs to be placed at eleven depths $(0.0 \mathrm{~cm}$ to $5.0 \mathrm{~cm})$ so as to determine the absorbed dose at those depths. Eleven (11) TLD chips were used for a particular field size. Six (6) different field sizes (5 $\mathrm{x} 5 \mathrm{~cm}$ to $10 \times 10 \mathrm{~cm}$ ) were used in this work. For each field size, the bolus material were arranged in layers and placed on a solid water phantom of dimensions $30 \mathrm{~cm}$ x $30 \mathrm{~cm}$ x $15 \mathrm{~cm}$ which provided the backscatter radiation. After the bolus material had been placed on the water phantom it was then irradiated with the Co-60 (Gammabeam X200) teletherapy machine at a source to surface distance $(\mathrm{SSD})$ of $80 \mathrm{~cm}$. The irradiation was done for each of the field sizes stated above. Figure 1 shows the experimental set-up for irradiating the material. After the material had been exposed to Cobalt- 60 gamma beam radiation, the equivalent absorbed dose of the TLDs was determined using the Harshaw 3500 TLD reader located at the TLD Laboratory of the Department of Physics and Engineering Physics, OAU, Ile-Ife. Evaluation of deviation of dose was carried out as follow [8]:

$$
\delta(\%)=100 \% \frac{\left(D_{\text {calc. }} D_{\text {measured }}\right)}{D_{\text {measuured }}}
$$

where $D_{\text {calc. }}$ is the calculated dose and $D_{\text {measured }}$ is the measured absorbed dose from the TLD.

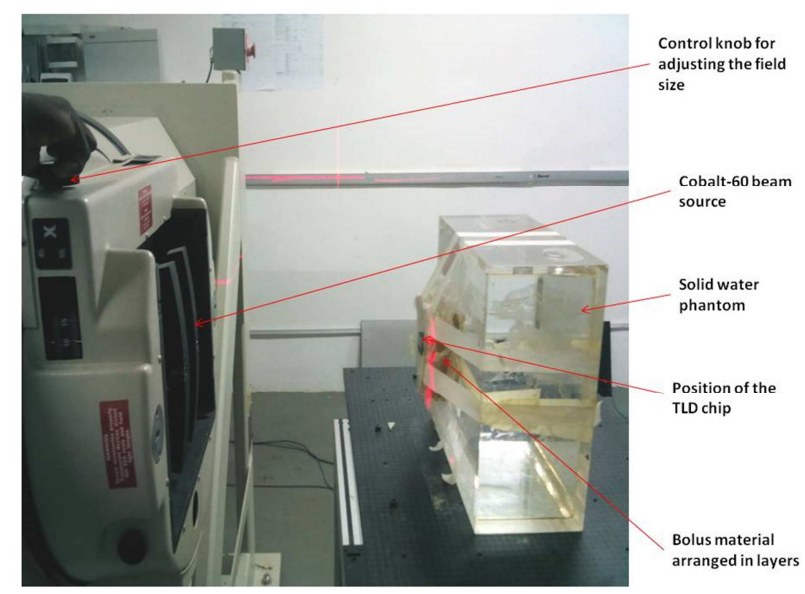

Figure 1. Experimental Set-up for Irradiating the Material.

\section{Result}

The value of the absorbed doses across the depth of the 
flexible fabricated bolus material when arranged in layers for $5 \times 5 \mathrm{~cm}^{2}, 6 \times 6 \mathrm{~cm}^{2}, 7 \times 7 \mathrm{~cm}^{2}$ and $8 \times 8 \mathrm{~cm}^{2}, 9 \times 9 \mathrm{~cm}^{2}, 10 \times$ $10 \mathrm{~cm}^{2}$ are presented in Table 1 and Table 2 respectively.

Table 1. Absorbed Dose for Field Size $5 \times 5 \mathrm{~cm}^{2}, 6 \times 6 \mathrm{~cm}^{2}$ and $7 \times 7 \mathrm{~cm}^{2}$.

\begin{tabular}{lllll}
\hline $\begin{array}{l}\text { S/N } \\
\text { O }\end{array}$ & $\begin{array}{l}\text { DEPTH } \\
(\mathbf{c m})\end{array}$ & $\begin{array}{l}\mathbf{5} \times \mathbf{5} \mathbf{c m}^{\mathbf{2}} \\
\text { DOSE }(\mathbf{G y})\end{array}$ & $\begin{array}{l}\mathbf{6 \times 6} \mathbf{c m}^{\mathbf{2}} \\
\text { DOSE }(\mathbf{G y})\end{array}$ & $\begin{array}{l}\mathbf{7 \times 7} \mathbf{c m}^{\mathbf{2}} \\
\text { DOSE }(\mathbf{G y})\end{array}$ \\
\hline 1 & 0.00 & 9.30 & 9.52 & 9.72 \\
2 & 0.50 & 68.80 & 69.02 & 69.30 \\
3 & 1.00 & 66.60 & 67.09 & 67.50 \\
4 & 1.50 & 64.82 & 65.12 & 65.66 \\
5 & 2.00 & 62.75 & 63.15 & 63.83 \\
6 & 2.50 & 60.70 & 61.34 & 62.03 \\
7 & 3.00 & 58.66 & 59.53 & 60.23 \\
8 & 3.50 & 56.82 & 57.69 & 58.48 \\
9 & 4.00 & 54.97 & 55.84 & 56.72 \\
10 & 4.50 & 53.15 & 54.01 & 54.90 \\
11 & 5.00 & 51.32 & 52.18 & 53.08 \\
\hline
\end{tabular}

Table 2. Absorbed Dose for Field Size $8 \times 8 \mathrm{~cm}^{2}, 9 \times 9 \mathrm{~cm}^{2}$ and $10 \times 10 \mathrm{~cm}^{2}$.

\begin{tabular}{|c|c|c|c|c|}
\hline $\begin{array}{l}\mathrm{S} / \mathbf{N} \\
\mathbf{O}\end{array}$ & $\begin{array}{l}\text { DEPTH } \\
(\mathrm{cm})\end{array}$ & $\begin{array}{l}8 \times 8 \mathrm{~cm}^{2} \\
\text { DOSE (Gy) }\end{array}$ & $\begin{array}{l}9 \times 9 \mathrm{~cm}^{2} \\
\text { DOSE (Gy) }\end{array}$ & $\begin{array}{l}10 \times 10 \mathrm{~cm}^{2} \\
\operatorname{DOSE}(\mathrm{Gy})\end{array}$ \\
\hline 1 & 0.00 & 9.99 & 10.30 & 10.50 \\
\hline 2 & 0.50 & 69.55 & 69.82 & 70.00 \\
\hline 3 & 1.00 & 68.01 & 68.35 & 68.60 \\
\hline 4 & 1.50 & 66.18 & 66.58 & 66.95 \\
\hline 5 & 2.00 & 64.35 & 64.80 & 65.29 \\
\hline 6 & 2.50 & 62.64 & 63.09 & 63.52 \\
\hline 7 & 3.00 & 60.93 & 61.37 & 61.75 \\
\hline 8 & 3.50 & 59.11 & 59.57 & 60.05 \\
\hline 9 & 4.00 & 57.30 & 57.77 & 58.35 \\
\hline 10 & 4.50 & 55.53 & 56.09 & 56.63 \\
\hline 11 & 5.00 & 53.75 & 54.40 & 54.91 \\
\hline
\end{tabular}

Table 3. Comparison of the Material Depth of Maximum Dose with some Tissue Equivalent Materials.

\begin{tabular}{lll}
\hline $\begin{array}{l}\text { Tissue Equivalent } \\
\text { Material }\end{array}$ & $\begin{array}{l}\text { Depth of Maximum } \\
\text { Dose (cm) }\end{array}$ & Source of Data \\
\hline Water & 0.5 & {$[13]$} \\
Superflab & 0.5 & {$[14]$} \\
Material for this work & 0.5 & This work \\
\hline
\end{tabular}

Table 3 presents the comparison of two tissue equivalent materials (water and Superflab) with the bolus material fabricated in this work in term of depth of maximum dose.

Figure 2 presents variation of absorbed dose with depth for different field sizes ranging from $5 \times 5 \mathrm{~cm}^{2}$ to $10 \times 10 \mathrm{~cm}^{2}$.

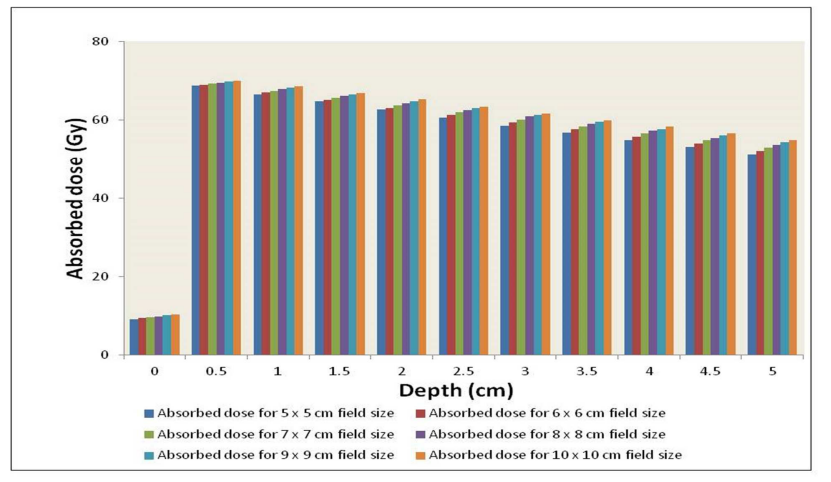

Figure 2. Variation of Absorbed Dose with Depth for Various Field Sizes.
Table 4. Percentage variation in Absorbed dose in water and the fabricated Bolus material.

\begin{tabular}{llll}
\hline $\begin{array}{l}\text { Depth } \\
\text { (cm) }\end{array}$ & $\begin{array}{l}\text { \% Variation for } \\
\text { Water }\end{array}$ & $\begin{array}{l}\text { \% Variation for } \\
\text { this study }\end{array}$ & $\begin{array}{l}\text { Difference in \% } \\
\text { Variation }\end{array}$ \\
\hline 1.00 & 3.50 & 2.04 & 1.46 \\
2.00 & 8.27 & 7.21 & 1.05 \\
3.00 & 14.11 & 13.36 & 0.75 \\
4.00 & 21.11 & 19.97 & 1.15 \\
5.00 & 27.92 & 27.48 & 0.44 \\
\hline
\end{tabular}

Table 4 shows the percentage variation of absorbed dose for depth ranging from $1 \mathrm{~cm}-5 \mathrm{~cm}$ taking maximum dose as the reference dose for $10 \mathrm{~cm} \times 10 \mathrm{~cm}$ field size for both water given by Memon et al. (2015) [13] and the material used in this study.

\section{Discussion}

From the result of the absorbed doses given in Table 1 and Table 2, it is noted that the maximum dose for each of the field sizes $5 \times 5 \mathrm{~cm}^{2}, 6 \times 6 \mathrm{~cm}^{2}, 7 \times 7 \mathrm{~cm}^{2}$ and $8 \times 8 \mathrm{~cm}^{2}, 9 \times$ $9 \mathrm{~cm}^{2}, 10 \times 10 \mathrm{~cm}^{2}$ are $68.80,69.02,69.30$ and 69.55, 69.82, 70.00 respectively. All these values occurred at a depth of 0.5 $\mathrm{cm}$. This is attributed to the fact that maximum dose do occurs at a depth of $0.5 \mathrm{~cm}$ when tissue equivalent material is irradiated with Cobalt-60 [6, 13, 15].

In term of depth of maximum dose, the comparison of the fabricated bolus in this work with that of water and Superflab tissue equivalent materials presented in Table 3 showed that the fabricated material is in agreement with that of water [13] and Superflab [14] since there depth of maximum dose occur at $0.5 \mathrm{~cm}$ for Cobalt- 60 radiation source.

The effects of increasing field size on absorbed dose for a given depth are clearly seen in Figure 2 . This is justified with the fact that an increase in the collimator field size usually contributes to absorbed dose at a given depth as a result of interaction of the radiation with the collimator which produces secondary radiation and is thus absorbed $[6,15]$. It should also be noted that because of the build up region of Cobalt 60 beam, there is higher difference in the value of the surface dose for all the field sizes when compared to the absorbed doses at a depth of $0.5 \mathrm{~cm}$. However, beyond the depth of maximum dose $(0.5 \mathrm{~cm})$, the absorbed dose decreases as the depth increases from $1 \mathrm{~cm}$ to $5 \mathrm{~cm}$ for all the field sizes because of the effects of inverse square law and attenuation of the Cobalt- 60 radiation as it traverses the fabricated bolus material arranged in layers.

It is observed from Table 4 that the $\%$ variation for both water and the material used for this study increases as the depth increases. The difference in the percentage for depth $1 \mathrm{~cm}, 2 \mathrm{~cm}, 3 \mathrm{~cm}, 4 \mathrm{~cm}$ and $5 \mathrm{~cm}$ are $1.46,1.05,0.75,1.15$ and 0.04 respectively. These deviations falls within the acceptable limit as stated by IAEA (2004) in which the variation should not be more than $2 \%$ [8].

\section{Conclusion}

The fabrication of alternative bolus material for Cobalt- 60 teletherapy using two locally available materials (Beeswax 
and Petroleum jelly) was successfully carried out. The cost of fabrication is less expensive and the process was not cumbersome. The value of the absorbed dose of Cobalt -60 measured with TLDs for various field size $(5 \mathrm{~cm} \times 5 \mathrm{~cm}$ to $10 \mathrm{~cm} \times 10 \mathrm{~cm})$ and depths $(0.0 \mathrm{~cm}$ to $5.0 \mathrm{~cm})$ shows that the maximum dose occurred at a depth of $0.5 \mathrm{~cm}$ for all the field size which is in agreement with the standard value for human tissue and tissue equivalent materials for Cobalt-60 photon beam irradiation. The dose for a given depth increases as the field size increases while the dose for a given field size beyond the depth of maximum dose reduces as the depth increases. The differences in the percentage variation are in tandem with IAEA (2004) report in which the deviation should not exceed $2 \%$.

This work shows that the fabricated bolus material of thickness $0.5 \mathrm{~cm}$ can be used as an alternative bolus material for Cobalt-60 Teletherapy in order to eliminate the skin sparing effect of Cobalt -60 radiation and hence, a solution to a major challenge for higher energy beam teletherapy.

\section{References}

[1] Park, J. W., Oh, S. A., Yea, J. W., and Kang, M. K. (2017). Fabrication of malleable three-dimensional-printed customized bolus using three-dimensional scanner. PloS one, $12(5), 1-9$.

[2] Khan, Y., Villarreal-Barajas, J. E., Udowicz, M., Sinha, R., Muhammad, W., Abbasi, A. N., \& Hussain, A. (2013). Clinical and dosimetric implications of air gaps between bolus and skin surface during radiation therapy. Journal of Cancer $\begin{array}{llll}\text { Therapy, } & 4 & (7), & 1251-1255 .\end{array}$ http://dx.doi.org/10.4236/jct.2013.47147.

[3] Walker, M., Cohen, N., and Menchaca, D. (2005). Play-doh and water-soaked gauze sponges as alternative bolus material for cobalt-60 teletherapy. Veterinary Radiology \& Ultrasound, $46 \quad$ (2): 179-181. http://dx.doi.org/10.1111/j.17408261.2005.00033.x.

[4] Malaescu, I., Marin, C. N., and Spunei, M. (2015). Comparative study on the surface dose of some bolus materials. International Journal of Medical Physics, Clinical Engineering and Radiation Oncology, 4 (04), 348-352. http://dx.doi.org/10.4236/ijmpcero.2015.44041.

[5] White, D., Booz, J., Griffith, R., Spokas, J., Wilson, I., Berger,
M., Constantinou, C., Goodman, L., Harder, D., Hubbell, J., Seltzer, S., Woodard, H. (1989). Tissue Substitutes in Radiation Dosimetry and Measurement, in: ICRU Report 44, International Commission on Radiation Units and Measurements, USA (1989), Pp. 1-14.

[6] Podgorsak, E. B., Andreo, P., Evans, M. D. C., Hendry, J. H., Horton, J. L., Izewska, J., Mijnheer, B. J.,... Tolli, H. (2005). Radiation oncology physics. Vienna: International Atomic Energy Agency, Pp. 172-244.

[7] Vidal, R. M. and do Nascimento Souza, D. (2012). A model for the characterization and selection of beeswaxes for use as base substitute tissue in photon teletherapy. Materials Sciences and Applications, 3 (04), 218-223. http://dx.doi.org/10.4236/msa.2012.34032.

[8] IAEA (2004). Commissioning and Quality Assurance of Computerized planning systems for Radiation therapy of Cancer. Vienna: International Atomic Energy Agency, Pp. 4654 .

[9] Govindaraj, K., Senthilkumar, S., Jeevan R. (2019). Dosimetric Characteristics of Transparent Bolus for External Beam Radiotherapy. Iranian Journal of Medical Physics. http://dx.doi.org/10.22038/IJMP.2019.37129.1470.

[10] Claude, K. P., Tagoe, S. N. A., Schandorf, C., and Amuasi, J. (2013). Fabrication of a tissue characterization phantom from indigenous materials for computed tomography electron density calibration. The South African Radiographer, 51 (1), $9-17$.

[11] https://www.candledeli.co.za/candle-making-tips-andideas/modelling-wax-sculpture wax.

[12] Beeswax. (n. d.). In Wikipedia. Retrieved February 15, 2019, from http://en.wikipedia.org/ wiki/Beeswax.

[13] Memon, S. A., Laghari, N. A., Mangi, F. H., Ahmad, F., Hussain, M. M., Palijo, S., Jhatyal, N., and Adeel, A. (2015). Analysis and verification of percent depth dose and tissue maximum ratio for Co-60 gamma ray beam. Worl App Sci J, 33 (1), 109-113.

[14] Nooshin, B., Hassan, A., Hassan, N., Mansureh, N., Mansur, N. (2013). Dose Measurement of Different Bolus Materials on Surface Dose. Journal of Radioprotection Research, 1 (1), 1013. http://dx.doi.org/10.12966/jrr.08.02.2013.

[15] Khan, F. M. and Gibbons, J. P. (2014). The physics of radiation therapy (5th ed.). Philadelphia, Lippincott Williams and Wilkins, Pp. 40, 240. 